\title{
Long-term efficacy of dietary weight loss in sleep apnoea/ hypopnoea syndrome
}

\author{
G. Sampol*, X. Muñoz*, M.T. Sagalés**, S. Martí*, A. Roca*, M. Dolors de la Calzada**, \\ P. Lloberes*, F. Morell*
}

Long-term efficacy of dietary weight loss in sleep apnoea/hypopnoea syndrome. G. Sampol, X. Muñoz, M.T. Sagalés, S. Martí, A. Roca, M. Dolors de la Calzada, P. Lloberes, F. Morell. CERS Journals Ltd 1998.

ABSTRACT: Weight loss is associated with clinical improvement in sleep apnoea/ hypopnoea syndrome (SAHS). The aim of this study was to ascertain whether the therapeutic efficacy of dietary weight loss is maintained in the long-term.

From a total of 216 overweight SAHS patients treated by only a weight reduction programme, 24 cured by this method (apnoea/hypopnoea index (AHI) at diagnosis 44.3 \pm 27.8 , after weight loss $3 \pm 3.1)$ were re-evaluated after a mean $( \pm \mathrm{sD})$ period of 94.3 \pm 27.4 months post-cure.

No correlation was found between changes in AHI and body mass index experienced by each patient in the two phases of the study (diagnosis to cure and cure to long-term follow-up), $r=0.29, p=0.156$, demonstrating a marked intra-individual variability. Six of the 13 patients who maintained their weight presented recurrence of SAHS (AHI 40.5 \pm 24.1 ) as did eight of the 11 who had regained weight (AHI 44.3 \pm 23.3). Weight maintenance was more frequent among patients who had continued to attend periodic appointments, $10 / 11$ versus $3 / 13$ ( $<<0.001)$.

In conclusion, weight-loss efficacy is maintained in the long-term in some sleep apnoea/hypopnoea syndrome patients. This study indicates the need for periodic follow-up of these patients as a reinforcement for weight maintenance and for early detection of the reappearance of sleep apnoea/hypopnoea syndrome.

Eur Respir J 1998; 12: 1156-1159.
*Serveis de Pneumologia and **Neurofisiologia, Hospital General Universitari Vall d'Hebron, Barcelona, Spain.

Correspondence: G. Sampol

Servei de Pneumologia

Hospital General Universitari Vall d'Hebron

Passeig Vall d'Hebron 119-129

Barcelona 08035

Spain

Fax: 34932746083

Keywords: Dietary therapy

sleep apnoea

weight loss

Received: October 101997

Accepted after revision May 121998

Financed in part by a grant from Agència d'Avaluació de Tecnologia Mèdica (Servei Catala de la Salut)
Clinical [1] and epidemiological [2] studies show obesity to be a risk factor for sleep apnoea/hypopnoea syndrome (SAHS) and weight loss occupies a place of special importance among general measures of SAHS treatment owing to the improvement it produces in respiratory disorders during sleep and in sleep architecture. The magnitude of this improvement varies greatly from patient to patient and has been described associated with both massive and minor weight loss [3-9]. However, there is a lack of knowledge as to whether or not these beneficial effects persist with age, another known risk factor for developing SAHS $[10,11]$. A known limitation of diet as a weight-losing method is the difficulty in maintaining the loss in the longterm [12].

With these considerations in mind, and in an attempt to ascertain whether the therapeutic efficacy of dietary weight loss is maintained in the long-term, a group of patients was studied who had previously been diagnosed with SAHS and cured more than 5 yrs ago using dietary weight loss as the only therapeutic measure.

\section{Patients and methods}

Between January 1985 and March 1990, 315 patients diagnosed with SAHS at the sleep laboratory in the authors' centre by whole-night polysomnography were followed. During this period, patients were managed by general re- commendations, a weight-reduction programme, nasal continuous positive airway pressure (nCPAP) $(n=60$, only available since October 1987) or uvulopalatopharyngoplasty $(n=29)$. Daytime sleepiness was categorized by a member of the team (A. Roca) according to the patient and the patients partner, if any, as: absent, slight, moderate, or severe. Two-hundred and sixteen overweight patients were initially treated on an outpatient basis by only a weight-reduction programme which included a low-calorie diet $(1,000$ $\mathrm{kcal} \cdot$ day $\left.^{-1}\right)$, encouragement to increase physical activity and periodic medical appointments for compliance reinforcement. No anorexiant drugs were used. Eleven patients were lost to follow-up and $104(51 \%)$ of the remaining 205 showed weight loss $>10 \%$ of initial weight. With the aim of reassessing the need for treatment, mainly the hypocaloric diet or nCPAP, which was not available or rejected at the time of diagnosis, an offer was made to repeat the polysomnography in these 104 patients, 101 of whom accepted. Sixty-seven of the latter presented with an apnoea/ hypopnoea index (AHI) Š10 and their characteristics are shown in table 1. Thirty-four patients presented with an $\mathrm{AHI}<10$, of whom 25 reported that they had stopped snoring completely and nine of whom reported that they continued to snore, but very slightly. Sleepiness at diagnosis (one slight, 22 moderate and 11 severe) disappeared in all patients. These patients were considered cured and advised to undertake a nutritionally adequate diet and maintain 
Table 1. - Characteristics of patients with apnoea/ hypopnoea index (AHI) Š10 events.h-1 after weight loss $(n=67)$

\begin{tabular}{lc}
\hline Age & $53.2 \pm 8.7(32-71)$ \\
Sex M/F & $59 / 8$ \\
BMI kg.m-2 & \\
$\quad$ At diagnosis & $31.5 \pm 5.0(27-47.2)$ \\
After weight loss & $25.9 \pm 2.9(23.9-41.0)$ \\
AHI events $\cdot{ }^{-1}$ & \\
$\quad$ At diagnosis & $52.3 \pm 23.2(12-105)$ \\
After weight loss & $44.2 \pm 25.6(11-12)$ \\
\hline
\end{tabular}

Data are shown as mean \pm SD (range). M: male; F: female; BMI: body mass index.

exercise habits. In three patients, weight loss was accompanied by complete abstention from a previously heavy alcohol intake and in another from sedatives. The remaining 30 patients presented no severe craniofacial malformations, nasal or oropharyngeal anatomical alterations other than uvula and soft palate hypertrophy, intercurrent disease that might influence weight loss maintenance, and were not taking antidepressants, hypnotics or sedatives. All were nondrinkers $(n=22)$ or had an alcohol intake $<10 \mathrm{~g}$. day $^{-1}(n=8)$ at diagnosis; alcohol consumption was not reevaluated when the second polysomnography was performed. Eighteen patients were nonsmokers, six smoked $<10$ cigarettes $\cdot$ day $^{-1}$ and six $>10$ cigarettes $\cdot$ day $^{-1}$; none of the smokers stopped smoking in the period between the two sleep studies. Eleven patients had maintained regular contact with a member of the team at the centre with two appointments each year at approximately six-month intervals and attempts were made to contact the remaining patients by telephone or letter. Two patients had died, two could not be located and two declined to participate in the study. The 24 remaining patients, 22 males and two females with a mean $( \pm \mathrm{SD})$ age of $49.6 \pm 5.9 \mathrm{yrs}$, agreed to answer a questionnaire on their general health, have daytime sleepiness assessed by the Epworth scale [13] and undergo physical examination, a new polysomnographic study and pulmonary function tests.

All sleep studies were performed during one night of sleep in the hospital and included continuous monitoring of electroencephalogram, electro-oculogram, submental electromyogram and electrocardiogram, arterial oxygen saturation $\left(\mathrm{S}_{\mathrm{a}}, \mathrm{O}_{2}\right)$, airflow at the nose and mouth monitored with thermistors, and chest and abdominal wall movements detected using strain gauges. Sleep was scored manually using standard criteria [14]. Total sleep time (TST) was measured from the moment the patient fell asleep to the final awakening, excluding wake time during sleep. Obstructive apnoea was defined as the absence of airflow at the nose and mouth $\breve{S} 10$ s with continued respiratory effort and hypopnoeas by a Š50\% reduction in oronasal airflow Š10 s associated with a decrease in $\mathrm{Sa}, \mathrm{O}_{2} \mathrm{~S} 4 \%$. The AHI was defined as the sum of all apnoeas and hypopnoeas divided by TST and expressed as events $\cdot \mathrm{h}^{-1}$.

\section{Statistics}

Data are expressed in the text and tables as mean \pm SD. Within-subject differences observed in the different phases of the study were analysed using Friedman and Wilcoxon nonparametric tests, with significance adjusted by the Bonferroni method when simultaneous multiple comparisons were performed. Between-subject differences were analysed using a Mann-Whitney U-test or Fisher's exact test where appropriate. The relation between changes in weight and AHI was evaluated using Pearson's correlation coefficient. Results were considered significant at $\mathrm{p}<0.05$ or, when Bonferroni-corrected, at $0.0166(0.05 / 3)$.

\section{Results}

The mean time elapsed between diagnosis and the polysomnography in which cure was established was 11.5 \pm 6.1 months (range 3.6-23.0) and between the latter and that performed in long-term follow-up 94.3 \pm 27.4 months (range 61-132). Mean values of body mass index (BMI), AHI and sleep architecture at different times of the study are shown in table 2. The mean decrease in BMI that led to a cure of SAHS (ýBMI1) was $5.6 \pm 2.5 \mathrm{~kg} \cdot \mathrm{m}^{-2}, 17.1 \pm 5.6 \%$ of its value at diagnosis. No correlation was observed between changes in BMI and AHI, either between the first and second $(\mathrm{r}=0.39, \mathrm{p}=0.054)$ or between the second and third polysomnographic recordings $(r=0.13, \mathrm{p}>0.2)$. ýAHI/ ýBMI values obtained in each patient in the two phases of the study also failed to show a significant correlation ( $\mathrm{r}=$ $0.299, \mathrm{p}=0.156$ ), demonstrating a marked intraindividual variability.

Depending on the weight gained between the time of cure and the end of the long-term follow-up (ýBMI2), patients were considered to have maintained their weight if ýBMI $2<1 / 2 y ́$ BMI 1 . Only one of the 11 patients who had followed periodic controls did not maintain their weight, whereas 10 of the 13 who had not attended controls had regained weight $(\mathrm{p}<0.001)$. The weight loss that led to a

Table 2. - Body mass index (BMI), apnoea/hypopnoea index (AHI) and sleep data values at diagnosis, cure and longterm follow-up

\begin{tabular}{lccc}
\hline & Diagnosis & Cure & Long-term follow-up \\
\hline BMI kg.m-2 & $32.8 \pm 4.6(27.8-48)$ & $27.2 \pm 3(24.7-37.7)^{*}$ & $30.8 \pm 5.5(24.5-47.4)^{\dagger}$ \\
AHI & $44.3 \pm 27.8(10-120)$ & $3 \pm 3.1(0-9)^{*}$ & $26.4 \pm 26.2(0-70)^{\dagger}$ \\
TST min & $315.4 \pm 73.8$ & $349.4 \pm 79.6$ & $323.8 \pm 81.9$ \\
ST 1-2 \% & $82.5 \pm 12.5$ & $62.8 \pm 13.5^{*}$ & $78.2 \pm 13.7$ \\
ST 3-4 \% & $9.0 \pm 8.5$ & $20.5 \pm 10.2^{*}$ & $10.0 \pm 9.2$ \\
REM \% & $8.4 \pm 6.1$ & $16.0 \pm 7.3^{*}$ & $11.5 \pm 7.9$ \\
\hline
\end{tabular}

Data are shown as mean \pm SD (range). TST: total sleep time; ST 1-2: stage 1-2 sleep; ST 3-4: stage 3-4 sleep; REM: rapid eye movement sleep; *: significant difference versus the values at diagnosis $(\mathrm{p}<0.005) ;:$ values at diagnosis and at cure $(\mathrm{p}<0.01)$; and $¥$ : the values at cure $(\mathrm{p}<0.01)$. 


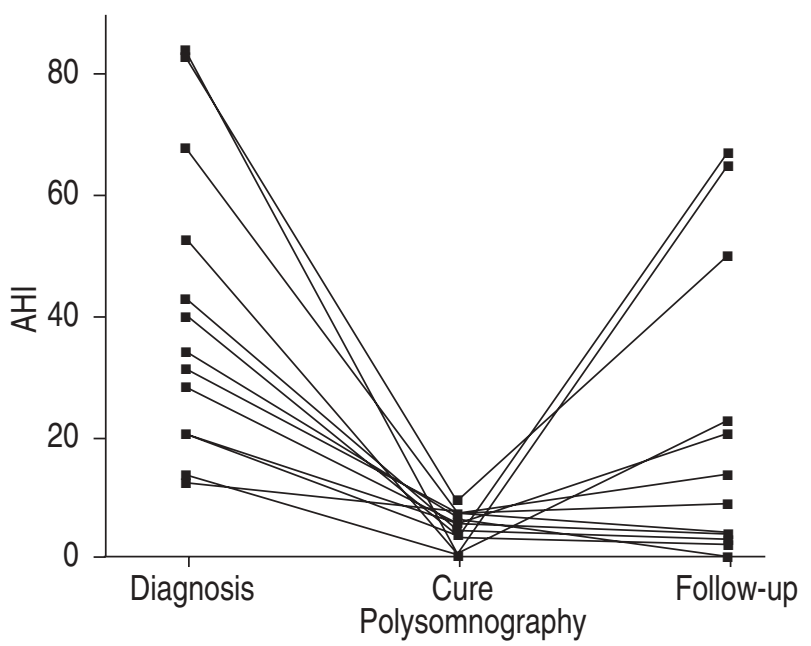

Fig. 1. - Evolution of apnoea-hypopnoea index (AHI) in patients who maintained weight loss.

cure was similar in the weight-maintaining and nonmaintaining groups, $5 \pm 2.3 \mathrm{~kg} \cdot \mathrm{m}^{-2}$ versus $6.3 \pm 2.7 \mathrm{~kg} \cdot \mathrm{m}^{-2}(\mathrm{p}>0.2)$. The individual evolution of AHI depending on maintenance or nonmaintainence of the weight at the time of cure is detailed in figures 1 and 2. Seven of the 13 patients who maintained the weight remained cured (AHI 3.1 \pm 3.1 events $\cdot \mathrm{h}^{-1}$ ), while the remaining six showed an AHI of $40.5 \pm$ 24.1 events $\cdot \mathrm{h}^{-1}$. AHI at diagnosis was similar in these two subgroups with no new weight gain: $33.9 \pm 17.9$ versus $48.7 \pm 30.6$ ( $p>0.2$ ). Eight of the 11 patients who had regained weight presented with recurrence of SAHS (AHI 44.3 \pm 23.3 ), while the other three, with AHI at diagnosis of 50, 27 and 10, had values of 9, 5 and 0 , respectively. Subjective sleepiness measured on the Epworth scale was greater in patients with an $\mathrm{AHI}>10$ events $\cdot \mathrm{h}^{-1}, 11.9 \pm 3.8$ versus $4.6 \pm 2.1(\mathrm{p}<0.001)$. On long-term follow-up, only two patients were using alcohol, $<10 \mathrm{~g} \cdot \mathrm{day}^{-1}$ each; one of them had maintained their weight and remained cured and the other had regained weight and presented with a recurrence of SAHS. Two patients were smokers; they maintained their weight and remained cured.

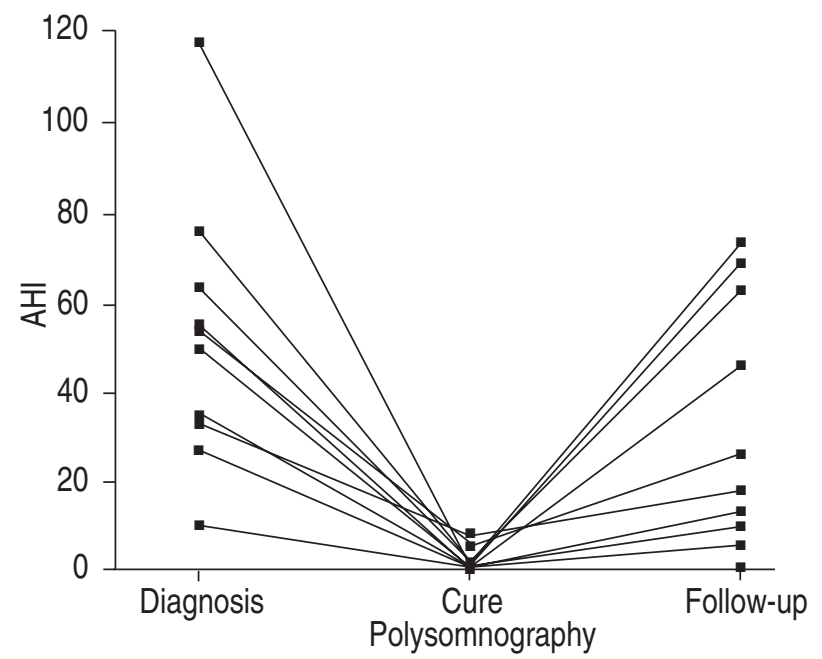

Fig. 2. - Evolution of apnoea-hypopnoea index (AHI) in patients who had regained weight.

\section{Discussion}

This study shows that, although almost half of the patients remained cured, relapse of SAHS in the long-term is frequent among those previously cured by dietary weight loss. The reappearance of SAHS was related in some patients to a new weight gain but was also observed in others who did not regain weight.

The effect of weight loss on SAHS is due to a decrease in pharyngeal collapsibility, demonstrated with decreases in BMI oscillating between $13 \%$ and $22 \%$ [6, 7, 9], but the change derived in the frequency of apnoea and hypopnoea episodes shows marked interindividual variability. This variability was even found in a group of "weight-dependent" SAHS patients and, for the first time to the authors' knowledge, long-term intraindividual variability was seen between changes in weight and changes in AHI induced by them. Although the internight variability of AHI is known, AHI is highly consistent from night to night in symptomatic SAHS patients with frequent apnoeas during sleep [15], such as those reported here. This fact, together with the improvement in symptoms and sleep structure parallel to the decrease in AHI and reappearance of symptoms with posterior rise in $\mathrm{AHI}$ in some patients on long-term follow-up, indicates that the values reported are representative of the situation in these patients. The findings strongly support the presence of other factors apart from weight implicated in recurrence of sleep-disordered breathing. It has been established in normal subjects that ageing produces pharyngeal narrowing and increased pharyngeal collapsiblity $[16,17]$, two facts related to SAHS [18, 19], which would explain its reappearance in some patients with overweight rates lower than those implicated previously in the development of upper airway obstructive episodes. In accordance with this, a recent study [20] in 14 morbidly obese patients showed an increased frequency of apnoeas 7.5 yrs after their decrease following a massive surgeryinduced weight loss which was unrelated to a new weight gain. However, those studies do not detail the evolution of the patients cured after the weight loss and do not include hypopnoeas, currently accepted as having a similar significance to apnoeas [21], in their results. In addition to considering hypopnoeas in the present analysis, SAHS was found to reappear in a group of patients with diet-treated nonmorbid obesity, the most usual situation in clinical practice.

The fact that three of the 11 patients who regained weight did not present SAHS is more difficult to explain. A change in upper- or lower-body distribution of fat on regaining weight could be implicated. However, this redistribution has not been observed previously in non-SAHS obese patients [22]. It may be speculated whether a more subtle redistribution of fat, affecting the excess fat in the cervical region and pharyngeal walls characteristic of SAHS [23, 24] might be involved. The amount of fat detected in these deposits has been correlated with AHI [25, 26], but not with general obesity, and its decrease in SAHS patients who present with decreased AHI after losing weight has been demonstrated [26]. During the selection period of the patients for the present study, neck circumference, a simple method of assessing neck fat was not measured; however, it would be interesting to ascertain whether changes therein bear any relationship to changes in AHI induced by weight loss or gain in some patients with SAHS. 
Despite the nonaggressive approach to the problem of weight loss and its maintenance, more than half of the patients did not regain weight in the long-term. This success rate is higher than that reported previously in both non-SAHS obese patients [12] and SAHS patients undergoing a very low calorie diet and who abandoned their periodical medical appointments [27], and was clearly related to periodic medical appointments for reinforcement of compliance, as indicated previously [12]. Effective treatment of SAHS implies an improvement in cognitive function and mood [28], which could have acted as a reinforcement mechanism not present in other obese patients without SAHS or with persistent SAHS after losing weight.

In summary, this study shows that diet-induced weight loss maintains its long-term efficacy in some sleep apnoea/ hypopnoea syndrome patients, particularly those checked periodically and who maintain their weight. However, the results also show that the long-term relationship between weight loss and regain and sleep apnoea/hypopnoea syndrome is complex; the syndrome may reappear with no new weight gain or, vice versa, not reappear despite a weight regain. This indicates the need for periodic followup of these patients, both as a reinforcement for maintaining the weight loss and for early detection of the reappearance of sleep apnoea/hypopnoea syndrome.

Acknowledgement: The authors thank C. O'Hara for help with the English translation.

\section{References}

1. Vgontzas A, Tan T, Bixler E, et al. Sleep apnea and sleep disruption in obese patients. Arch Intern Med 1994; 154: 1705-1711.

2. Young T, Palta M, Dempsey J, et al. The occurrence of sleep-disordered breathing among middle-aged adults. $N$ Engl J Med 1993; 328: 1230-1235.

3. Harman EM, Wynne JW, Block AJ. The effect of weight loss on sleep disordered breathing and oxygen desaturation in morbidly obese men. Chest 1982; 82: 291-294.

4. Smith PL, Gold AR, Meyers DA, Haponik EF, Bleeker ER. Weight loss in mildly to moderately obese patients with obstructive sleep apnoea. Ann Intern Med 1985; 103: 850-855.

5. Sugerman HJ, Fairman RP, Baron PL, Kwentus JA. Gastric surgery for respiratory insufficiency of obesity. Chest 1986; 90: 81-86.

6. Suratt PM, McTier RF, Findley LJ, Pohl SL, Wilhoit SC. Changes in breathing and the pharynx after weight loss in obstructive sleep apnoea. Chest 1987; 4: 631-637.

7. Rubinstein I, Colapinto N, Rotstein LE, Brown IG, Hoffstein V. Improvement in upper airway function after weight loss in patients with obstructive sleep apnea. Am Rev Respir Dis 1988; 138: 1192-1195.

8. Pasquali R, Colella P, Cirignotta F, et al. Treatment of obese patients with obstructive sleep apnea syndrome (OSAS): effect of weight loss and interference of otorhinolaryngoiatric pathology. Int J Obesity 1990; 14: 207217.

9. Schwartz AR, Gold AR, Schubert N, et al. Effect of weight loss on upper airway collapsability in obstructive sleep apnea. Am Rev Respir Dis 1991; 144: 494-498.
10. Lugaresi E, Cirignotta F, Gerardi R, Montagna P. Snoring and sleep apnea: natural history of heavy snorers disease. In: Guilleminault C, Partinen M, eds. Obstructive Sleep Apnea Syndrome: Clinical Research and Treatment. New York, Raven Press, 1990; pp. 25-36.

11. Redline S, Young T. Epidemiology and natural history of obstructive sleep apnea. Ear Nose Throat J 1993; 72: 2026.

12. NIH Technology Assessment Conference Panel. Methods for voluntary weight loss and control. Ann Intern Med 1993; 119: 764-770.

13. Johns MW. A new method for measuring daytime sleepiness: the Epwonh sleepiness scale. Sleep 1991; 14: 540545.

14. Rechtschaffen A, Kales A. A manual of standardized terminology, techniques and scoring system of sleep stages of human subjects. Washington, DC, National Institutes of Health, 1968; publication No. 204.

15. Wittig RM, Romaker A, Zorick FJ, et al. Night-to-night consistency of apneas during sleep. Am Rev Respir Dis 1984; 129: 244-246.

16. White DP, Lombard RM, Cadieux RJ, Zwillich CW. Pharyngeal resistance in normal humans: influence of gender, age, and obesity. J Appl Physiol 1985; 58: 365-371.

17. Brown IG, Zamel N, Hoffstein V. Pharyngeal cross-sectional area in normal men and women. J Appl Physiol 1986; 61: 890-895.

18. Bradley T, Brown I, Grossman R, et al. Pharyngeal size in snorers, nonsnorers, and patients with obstructive sleep apnea. N Engl J Med 1986; 315: 1327-1331.

19. Gleadhill IC, Schwartz AR, Schubert N, et al. Upper airway collapsibility in snorers and in patients with obstructive sleep hypopnea and apnea. Am Rev Respir Dis 1991; 143: 1300-1303.

20. Pillar G, Peled R, Lavie P. Recurrence of sleep apnea without concomitant weight increase 7.5 years after weight reduction surgery. Chest 1994; 106: 1702-1704.

21. Gould GA, Whyte KF, Rhind GB, et al. The sleep hypopnea syndrome. Am Rev Respir Dis 1988; 137: 895-898.

22. Wadden TA, Barlett S, Letizia KA, et al. Relationship of dieting history to resting metabolic rate, body composition, eating behaviour and subsequent weight loss. Am J Clin Nutr 1992; 56: 203S-208S.

23. Horner R, Mohiaddin R, Lowell DG, et al. Sites and sizes of fat deposits around the pharynx in obese patients with obstructive sleep apnoea and weight matched controls. Eur Respir J 1989; 2: 613-622.

24. Davies RJO, Stradling JR. The relationship between neck circumference, radiographic pharyngeal anatomy, and the obstructive sleep apnoea syndrome. Eur Respir J 1990; 3: 509-514.

25. Katz I, Stradling J, Slutsky AS, Zamel N, Hoffstein V. Do patients with obstructive sleep apnea have thick necks? Am Rev Respir Dis 1990; 141: 1228-1231.

26. Shelton KE, Woodson H, Gay S, Suratt PM. Pharyngeal fat in obstructive sleep apnea. Am Rev Respir Dis 1993; 148: 462-466.

27. Suratt PM, McTier RF, Findley LJ, Pohl SL, Wilhoit SC. Effect of very-low-calorie diets with weight loss on obstructive sleep apnea. Am J Clin Nutr 1992; 56: 182S-184S.

28. Engleman HM, Martin SE, Deary IJ, Douglas NJ. Effect of continuous positive airway pressure treatment on daytime function in sleep apnoea/hypopnoea syndrome. Lancet 1994; 343: 572-575. 